\title{
RESENHA
}

\section{CONHECIMENTO ESCOLAR E DEFICIÊNCIA INTELECTUAL: DADOS DA REALIDADE}

\author{
Cláudio Rodrigues da Silva ${ }^{1}$ \\ Agnes Iara Domingos Moraes ${ }^{1}$ \\ Universidade Estadual Paulista (UNESP) ${ }^{1}$
}

OLIVEIRA, Anna Augusta Sampaio de. Conhecimento escolar e deficiência intelectual: dados da realidade. Curitiba: CRV, 2018. 168 p. ISBN 978-85-444-2020-1

"Um texto bem fundamentado, articulado e consistente" e que "representa uma grande contribuição" para a Educação. Essas são palavras do Prof. Sadao Omote ao fazer, no Prefácio (p. 18), menção ao livro Conhecimento escolar e deficiência intelectual: dados da realidade, de autoria de Anna Augusta Sampaio de Oliveira, publicado em 2018, pela CRV.

Anna Augusta é professora de Graduação e Pós-Graduação da Faculdade de Filosofia e Ciências, campus Marília, da Universidade Estadual Paulista (Unesp). Suas "andanças" incluem atividades como professora, palestrante, pesquisadora, assessora, gestora, bem como, autora de diversos artigos, capítulos e livros relacionados à Educação Especial, com foco na Deficiência Intelectual e na avaliação da aprendizagem escolar na perspectiva da Educação Inclusiva. Várias de suas produções são decorrentes de pesquisas empíricas, como é o caso do livro em tela, que, como indicado no subtítulo, apresenta "dados da realidade".

Esse livro é uma contribuição relevante, tanto em termos da temática abordada quanto em termos da conjuntura de publicação, pois, conforme Omote (p. 18):

No cenário atual das discussões sobre a educação inclusiva, há forte demanda para um avanço expressivo nos nossos conhecimentos e práticas da educação inclusiva. É imprescindível alcançar um outro patamar, quiçá, até chegarmos a uma situação na qual a educação escolar de crianças e jovens com deficiência intelectual não cause estranheza, constrangimento nem percepção antecipada de dificuldades e fracassos.

Os dados apresentados são decorrentes principalmente de experiências da autora na concepção e aplicação do Referencial de Avaliação de Aprendizagem na área da Deficiência Intelectual (RAADI), elaborado com professores da Rede Municipal de Educação de São Paulo (RMESP). O RAADI, segundo a autora (p. 84), avalia os diversos fatores ou sujeitos envolvidos no processo educativo e "[...] pode oferecer ao professor subsídios e in- 
dicativos na busca de alternativas de avaliação da aprendizagem a partir da base curricular do ensino fundamental".

Tendo como referencial teórico o materialismo histórico dialético, as contribuições de Vygotsky e de autores que trabalham na perspectiva histórico-cultural, Anna Augusta (p. 14) defende a tese de que "[...] os escolares com deficiência intelectual são capazes de aprenderem os conteúdos escolares numa perspectiva educacional inclusiva”.

Em termos estruturais-formais, o livro é composto por cinco capítulos, além da Apresentação, do Prefácio, da parte conclusiva - intitulada "Algumas considerações - $\mathrm{O}$ entrelaçamento entre reflexões e possibilidades” - e das Referências. Destacam-se, a seguir, alguns pontos problematizados pela autora nos capítulos e nas considerações.

No primeiro capítulo, "Deficiência intelectual: o resgate do sujeito histórico", Anna Augusta aborda, desde uma perspectiva da teoria histórico-cultural, a questão da constituição do sujeito histórico na área da deficiência intelectual. Assim, sujeitos, subjetividade e educação são analisados a partir das suas relações necessárias com o momento histórico e com a sociedade em que estão inseridos. O desenvolvimento das pessoas com deficiência intelectual relaciona-se mais com as condições sociais do que com as biológicas. Segundo a autora, um desafio posto à Educação Especial e à Pedagogia é a superação dos processos naturais por intermédio do desenvolvimento cultural, considerando-se as compensações, bem como, a necessidade de mediações pedagógicas.

"Escolarização e aprendizagem: o enfoque histórico-cultural" é o segundo capítulo, no qual a autora argumenta que, numa perspectiva histórica e humanizadora da deficiência intelectual, é incoerente manter práticas ou concepções pedagógicas ultrapassadas, equivocadas ou inconsistentes acerca da deficiência intelectual. Conquanto em termos de discursos oficiais tenham ocorrido mudanças na concepção de educação das pessoas com deficiência intelectual, a rotina escolar ainda está distante do preconizado pelo paradigma da Educação Inclusiva. Intencionalidade é um quesito indispensável para que sejam efetivadas mudanças radicais, tanto nas práticas docentes quanto na gestão da escola.

Em "Notas sobre a inclusão escolar e escolarização na área da deficiência intelectual", terceiro capítulo, Anna Augusta registra o intenso debate nacional sobre a inclusão escolar, que envolve vários fatores - gestão escolar, formação de professores, práticas pedagógicas, entre outros. Esses fatores envolvem disputas teórico-práticas em torno de concepções de educação e de deficiência intelectual, disputas essas que impactam em todos os aspectos do currículo. Diversas pesquisas apontam dificuldades no processo de inclusão escolar, principalmente das pessoas com deficiência intelectual, cujo processo de ensino-e-aprendizagem requer revisão radical das concepções e práticas pedagógicas, tanto no apoio especializado quanto nas salas comuns. Essa revisão radical demanda intencionalidade, para superação dos desafios implicados. Ainda que não seja o único fator envolvido, a atuação dos professores é fundamental nesse processo, visando alternativas, estratégias e recursos para compensação e superação das dificuldades inerentes à deficiência intelectual.

"Avaliação escolar e da aprendizagem: em busca de referentes", quarto capítulo, trata da temática central do livro, qual seja, a questão da avaliação. Anna Augusta considera a avaliação o ponto "nuclear da escola", pois permite conhecer as condições reais de apren- 
dizagem dos estudantes com deficiência intelectual, de forma que se possa realizar uma "atuação pedagógica intencional" com vistas ao desenvolvimento das funções psicológicas superiores. Assim, a avaliação necessita ser adequada às especificidades desse público, de maneira a propiciar dados condizentes com a realidade e a possibilitar adequações ou outras intervenções necessárias.

No capítulo quinto, intitulado "Os resultados da aprendizagem: além das aparências", com base no RAADI, Anna Augusta apresenta, com aporte de diversos gráficos, a descrição e a análise dos desempenhos acadêmicos em Língua Portuguesa e em Matemática dos estudantes com deficiência intelectual da RMESP. A autora (p. 137) sustenta que foi possível "[...] demonstrar, por meio dessa pesquisa, [...] [a] condição de acesso [dos estudantes com deficiência intelectual] ao currículo, mesmo que de forma particular e específica". Esses resultados são importantes, especialmente porque pesquisas acadêmico-científicas apontam que o sistema de ensino não atende aos princípios da Educação Inclusiva, principalmente em se tratando de estudantes com deficiência intelectual.

Da parte final do livro, denominada "Algumas considerações - O entrelaçamento entre reflexões e possibilidades", destacam-se alguns pontos. Anna Augusta é enfática no que se refere a determinados aspectos cruciais, especialmente no que tange à relação entre as dimensões individual e coletiva, social e biológica, educação comum e Educação Especial. A autora aborda, ainda, a formação de professores, dimensão-chave no processo de ensino-e-aprendizagem, as funções sociais do professor e da escola, a relação necessária entre as dimensões pedagógica e gestora, entre outros.

No entanto, concomitantemente a isso, um aspecto fundamental a ser considerado é a relação entre a educação e a sociedade que a concebe, especialmente no que tange ao modo de produção, fator-chave na configuração das relações sociais, inclusive das concepções de humano, de trabalho, de educação, entre outras, concepções essas que impactam, direta ou indiretamente, nas concepções de inclusão e de deficiência intelectual. É inerente ao sistema capitalista as hierarquizações sociais verticais, o individualismo e a competição, entre outros princípios incompatíveis com a Educação Inclusiva na acepção da teoria histórico-cultural.

Coerentemente com o referencial teórico adotado, Anna Augusta refuta abordagens simplistas, fenomênicas, subjetivistas ou idealistas. Isso requer que se coloque em tela especialmente a questão das condições materiais de vida, quesito fundamental para condições elementares de ensino-e-aprendizagem. Por isso a importância de se considerar a inter-relação entre deficiência intelectual e outras categorias analíticas, por exemplo, classe social, gênero - e acrescenta-se - sexualidade, etnia, entre outras. A autora confere a devida importância àqueles aspectos cruciais enunciados. Todavia, não os apresenta como secundários, nem isoladamente como raiz ou solução dos problemas da educação. Desse modo, reconhece limites e potencialidades da educação para o processo de transformações sociais.

Anna Augusta registra a implementação do RAADI também no ciclo II e na EJA. Considera-se uma iniciativa importante, haja vista a necessidade de adequações e de apoio especializado em todos os níveis, etapas ou modalidades da educação escolar. Esse avanço é indispensável para que estudantes com deficiência intelectual tenham maiores possibilidades de acesso, permanência e apropriação dos conhecimentos escolares também em 
outros níveis ou modalidades da educação. Aliás, a Educação Especial continua rudimentar ou ausente de matrizes curriculares de diversos cursos de Licenciatura.

A avaliação da aprendizagem na lógica da Educação Inclusiva, segundo a autora, é complexa, polêmica e representa uma lacuna em termos de produções acadêmico-científicas. Considera-se, partindo dos apontamentos da autora, a importância, entre outros fatores, de uma consistente formação docente também em fundamentos - política, filosofia, história, psicologia, dentre outros - da educação e da sociedade. Isso pode contribuir para a compreensão das implicações e dos pressupostos da Educação Inclusiva em uma acepção crítica e sua incompatibilidade com concepções meritocráticas de avaliação, que visam principal ou unicamente a classificação, hierarquização, reprovação ou aprovação dos estudantes. Na abordagem meritocrática, a avaliação torna-se um instrumento excludente; já numa acepção crítica de Educação Inclusiva, deve servir para melhoria das condições de ensino-e-aprendizagem. Entretanto, há que se considerar diversos outros fatores que, em alguma medida, extrapolam a alçada decisória da escola e dos professores, por exemplo, as avaliações externas de larga escala, que tendem a impactar contraditoriamente no cotidiano escolar.

Como destaca Omote, Anna Augusta tem "convicção" quanto à capacidade de aprendizagem dos estudantes com deficiência intelectual. Essa convicção, para alguns setores, pode configurar-se uma utopia irrealizável. No entanto, para a autora (p. 58), trata-se de uma utopia necessária, exequível e que, para ser alcançada, depende de intencionalidade: "Talvez esta seja a grande utopia que sustenta nossos sonhos e nossas lutas, simplesmente a escola cumprir seu papel diante de todos os escolares, apenas isto!" E, para "isto", considera-se indispensável "[...] lutar por uma escola pública, laica, democrática, inclusiva e popular" (OLIVEIRA, 2018, p. 144).

Dados dos autores

\section{Cláudio Rodrigues da SiLva}

Doutorando (Linha de "Políticas Educacionais, Gestão de Sistemas e Organizações, Trabalho e Movimentos Sociais") no Programa de Pós-Graduação em Educação da Faculdade de Filosofia e Ciências da Universidade Estadual Paulista (Unesp). silvanegrao@gmail.com

\section{Agnes Iara Domingos Moraes}

Doutoranda em Educação, com período sanduíche na Universidad de Salamanca - Espanha, Mestre em Educação, Especialista em Atendimento Educacional Especializado: área da Deficiência Intelectual e Graduada em Pedagogia com Habilitação em Deficiência Intelectual, todos pela Faculdade de Filosofia e Ciências da Universidade Estadual Paulista "Júlio de Mesquita Filho". Integrante do "Grupo de Estudos e Pesquisas sobre Cultura e Instituições Educacionais" (Gepcie) e do "Grupo de Pesquisa História da Educação e do Ensino de Língua e Literatura no Brasil” (Gpheellb).moraes.aid@gmail.com

Submetido em:23-4-2018

Aceito em: 28-5-2018 